\title{
RODADA DOHA E A POSSÍVEL REDUÇÃO DE BARREIRAS TARIFÁRIAS E NÃO TARIFÁRIAS: UMA ESTIMATIVA DOS BENEFÍCIOS PARA O BRASIL POR MEIO DO MODELO DE EQUILÍBRIO GERAL COMPUTÁVEL
}

\author{
Alessandra Biavati Rizzotto ${ }^{a}$ \\ André Filipe Zago de Azevedo ${ }^{b}$ \\ ${ }^{a}$ Mestra em Economia pela Universidade do Vale do Rio dos Sinos (UNISINOS). Porto Alegre, RS, Brasil. \\ ORCID: https://orcid.org/0000-0001-6551-449X.

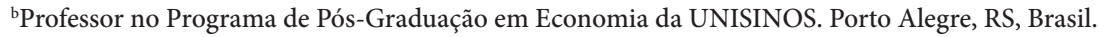 \\ ORCID: https://orcid.org/0000-0002-2745-0381.
}

Artigo recebido em 23/10/2018 e aceito para publicação em 14/04/2019.

RESUMO: O objetivo do artigo é simular reduções de barreiras tarifárias e não tarifárias no âmbito multilateral da Rodada Doha e verificar quais seriam os benefícios para o Brasil. Para tanto, foi estimado um modelo de equilíbrio geral computável, por meio do software GTAP, e quatro cenários foram simulados. Os resultados mostram que, para o Brasil, nos cenários em que só são incorporadas reduções de tarifas, o setor primário e de agroindústria seriam os mais beneficiados. A redução multilateral das barreiras não tarifárias (BNT) favoreceria, especialmente, os setores industriais, de maior conteúdo tecnológico. Em relação ao bem-estar, os cenários que incorporam redução de BNT ou reduções combinadas de BNT e tarifas são os mais benéficos para todas as regiões incluídas no estudo, com ganhos mundiais que podem alcançar mais de US\$ 1 trilhão.

PALAVRAS-CHAVE: Rodada Doha; barreiras tarifárias; barreiras não tarifárias; exportações; bem-estar.

CLASSIFICAÇÃO JEL: F15; C68. 


\title{
THE DOHA ROUND AND THE EFFECTS OF THE REDUCTION OF TARIFF AND NON- TARIFF BARRIERS: AN ESTIMATION OF BENEFITS FOR BRAZIL USING A COMPUTABLE GENERAL EQUILIBRIUM MODEL
}

\begin{abstract}
The objective of this article is to simulate reductions of tariff and nontariff barriers, in the multilateral scope of the Doha Round, and to verify the benefits for Brazil. Therefore, a computable general equilibrium model was estimated using the GTAP software, and four scenarios were simulated. The results show that, for Brazil, in the scenarios in which only tariff reductions are incorporated, the primary and agroindustry sectors would be the most benefited. The multilateral reduction of nontariff barriers to trade (NTB) would favor, especially, the industrial sectors, of greater technological content. Concerning well-being, scenarios incorporating reductions in NTB or combined reductions in NTB and tariffs are the most beneficial for all regions included in the study, with worldwide gains that can reach over \$ 1 trillion.
\end{abstract}

KEYWORDS: Doha Round; tariff barriers; non-tariff barriers; exports; welfare. 


\section{INTRODUÇÃO}

Em 1948 teve início um acordo provisório de comércio denominado General Agreements on Tariffs and Trade (GATT), assinado por 23 países, que tinha como objetivo diminuir as barreiras comerciais e garantir um acesso mais equitativo aos mercados. $\mathrm{O}$ texto básico de 1947, que foi escrito durante a Rodada de negociações de Genebra, ${ }^{1}$ foi ampliado ou modificado por novos códigos e acordos, e o GATT, que em suas origens versava basicamente sobre tarifas, foi incorporando disciplinas sobre medidas não tarifárias, que se tornaram mais importantes conforme as tarifas foram sendo reduzidas (RÊGO, 1996).

A Organização Mundial do Comércio (OMC) entrou em funcionamento no dia $1^{\circ}$ de janeiro de 1995, com a finalidade de administrar o sistema multilateral do comércio, resultante da Rodada Uruguai (1986/1993). A OMC substituiu o GATT, que tinha caráter provisório e não tinha base institucional, ao contrário da $\mathrm{OMC}$, que é uma organização permanente, com personalidade jurídica própria (RÊGO, 1996). A Rodada Doha foi a primeira rodada de negociações da OMC, que teve início em 2001 e se estende até os dias atuais. Inúmeros impasses no contexto multilateral afloraram das mesas de negociação na OMC, principalmente na área agrícola, de especial interesse para o Brasil, tornando a presente rodada a mais longa de toda a história do GATT/OMC.

Nas primeiras rodadas de negociações do GATT/OMC, foram os países desenvolvidos que ativamente participaram das decisões, e os países em desenvolvimento ficaram às margens do processo. Com isso, o setor de manufaturas (de interesse dos países desenvolvidos) foi o que teve as tarifas mais reduzidas. Porém, a Rodada Uruguai marcou a maior inserção dos países em desenvolvimento nos processos decisórios, e, apesar de o setor primário e têxtil ainda apresentar tarifas relativamente mais elevadas que o setor de manufaturas, as mesmas vêm caindo (REIS et al., 2015). Sendo assim, cresce a importância de uma análise sobre o aumento do uso de medidas não tarifárias.

Muitos estudos, no âmbito nacional, propõem-se a analisar o impacto de reduções tarifárias, tanto regionalmente quanto multilateralmente, tais como Arêdes e Pereira (2009), Sampaio e Sampaio (2009), Rodrigues, Burnquist e Costa (2011). Porém, ainda

\footnotetext{
Após a Rodada de Genebra, foram realizadas mais sete rodadas de negociações multilaterais sob a coordenação do GATT: Rodada Annecy (1949), Rodada Torquay (1950/51), segunda Rodada Genebra (1955/56), Rodada Dillon (1960/61), Rodada Kennedy (1963/67), Rodada Tóquio (1973/79) e Rodada Uruguai (1986/93).
} 
há poucos trabalhos na literatura brasileira que incorporam também o impacto das barreiras não tarifárias (BNT), como o do Instituto de Estudos para o Desenvolvimento Industrial (IEDI, 2014).

Dado que a participação ativa dos países em desenvolvimento nas mesas de negociações da OMC, juntamente com o início da liberalização dos produtos primários, começou, de fato, somente após a Rodada Uruguai, é de se esperar que os benefícios proporcionados pela OMC sejam maiores quanto maior for o engajamento das nações em buscar reduções de barreiras tarifárias e não tarifárias dos produtos de seus interesses. Especificamente para o Brasil, sete dos dez ${ }^{2}$ produtos mais exportados pelo Brasil em 2016 eram oriundos do agronegócio (UN COMTRADE, 2017). Logo, prevê-se que uma maior liberalização desse setor gere um aumento adicional significativo no comércio internacional do país. Sendo assim, estudos que busquem quantificar os efeitos da liberalização multilateral da Rodada de Doha, e também analisar o nível de bem-estar tanto no âmbito nacional, como no mundial, servem como base para justificar o apelo a uma maior liberalização comercial. Sendo assim, o objetivo desse artigo é verificar os benefícios para o Brasil de uma redução multilateral de barreiras tarifárias e não tarifárias, nos moldes propostos pela OMC, com ênfase no setor primário.

O método comumente utilizado para a simulação de reduções tarifárias e não tarifárias são os modelos de equilíbrio geral. Os modelos de equilíbrio geral computáveis (EGC) especificam todas as suas relações econômicas em termos matemáticos e as agrupam de forma a permitir que o modelo preveja a mudança de variáveis como preços, produto e bem-estar econômico resultantes de uma mudança nas políticas econômicas, dadas as informações sobre tecnologia (os insumos necessários para produzir uma unidade do produto), políticas e preferências dos consumidores (GTAP, 2011). O software utilizado nesse estudo é o GTAP, com a base de dados de sua versão 9.0, com o equilíbrio inicial sendo gerado em 2011 . $^{3}$

$\mathrm{O}$ artigo está dividido em quatro seções, além desta introdução. A seção 2 examina a evolução da Rodada Doha. A seção 3 aborda o modelo de equilíbrio geral, bem como

2 Os dez produtos mais exportados pelo Brasil em 2016: soja, mesmo triturada, exceto para semeadura; minérios de ferro não aglomerados e seus concentrados; óleos brutos de petróleo ou de minerais betuminosos; outros açúcares de cana; tortas e outros resíduos sólidos da extração do óleo de soja; pasta química de madeira de não conífera, à soda ou sulfato, semibranqueada ou branqueada - celulose; café não torrado, não descafeinado; pedaços e miudezas comestíveis de galos e galinhas da espécie doméstica, congelados; milho, exceto para semeadura; barcos-faróis, guindastes, docas, diques flutuantes e outras embarcações em que a navegação e acessória da função principal.

3 O modelo GTAP padrão é um modelo de equilíbrio geral multirregional e multissetorial, com concorrência perfeita e retornos constantes de escala. 
o modelo específico do GTAP, e os cenários e agregações simulados na dissertação. A seção 4 apresenta os resultados de reduções tarifárias e não tarifárias sobre as exportações brasileiras e o bem-estar de todas as regiões do trabalho, bem como uma seção com a análise de sensibilidade dos resultados, para verificar a robustez dos cenários simulados. Por fim, na última seção, apresentam-se as conclusões.

\section{REVISÃO DE LITERATURA}

Diversos estudos que simulam a redução de tarifas e medidas não tarifárias mostram aumento do nível geral de bem-estar mundial proveniente da maior liberalização. Arêdes e Pereira (2009) utilizaram o modelo de equilíbrio geral GTAP com o objetivo de avaliar os impactos da Rodada Doha sobre o agronegócio, a economia e o bemestar no Brasil e no Mercosul. Os autores analisaram três cenários de redução de tarifas de importação para produtos agrícolas, manufaturas e de serviços. O primeiro cenário testado foi de uma redução em 50\% das tarifas de importação de produtos agrícolas e de $25 \%$ dos produtos manufaturados e serviços; a segunda simulação testada por eles foi uma redução em $75 \%$ das tarifas de importação de produtos agrícolas e de $50 \%$ dos produtos manufaturados e serviços; e, o último cenário analisou uma redução em $100 \%$ das tarifas de importação de produtos agrícolas e de 50\% dos produtos manufaturados e serviços.

O estudo demonstrou que o setor agrícola do Brasil e do Mercosul foi competitivo em todos os cenários, elevando a produção, a exportação e diminuindo as importações desse setor. Porém, o mesmo não ocorreu com os setores de manufaturas e serviços, em que as vantagens competitivas favoreceram o Nafta e a UE. Foi verificada ainda uma elevação do PIB e do bem-estar no Brasil e no Mercosul em todos os cenários (ARÊDES e PEREIRA, 2009). Os autores alertam, no entanto, que uma política de abertura comercial, como analisada no estudo, beneficia a maioria das commodities agrícolas no Brasil e no Mercosul em detrimento dos setores de manufaturados e serviços, o que eleva a vulnerabilidade de suas balanças comerciais a efeitos adversos, como choques de queda de preços e de barreiras sanitárias agrícolas às exportações.

Figueiredo et al. (2010) avaliaram o impacto dos subsídios norte-americanos no setor agrícola na expansão do agronegócio brasileiro. De acordo com os autores, nas rodadas de negociações multilaterais da OMC subsiste forte debate com intuito de eliminar as subvenções agrícolas nos países desenvolvidos. No entanto, os Estados Unidos têm expandido o volume desses subsídios, causando distorções no comércio agrícola mundial. Figueiredo et al. (2010) analisaram o impacto dos subsídios norteamericanos Loan Deficiency Payments, concedidos no período de 2002 a 2007, sobre 
o crescimento do agronegócio brasileiro, por meio de um modelo de equilíbrio geral computável. Os resultados mostram que a redução dos subsídios nos EUA levaria ao crescimento da produção agroindustrial brasileira e ampliaria o superavit na balança comercial desse setor, com crescimento das exportações e importações. Assim, cortes nesses subsídios contribuiriam para maior competitividade das exportações brasileiras e criariam oportunidades para o crescimento do agronegócio (FIGUEIREDO et al., 2010).

Sbarai e Miranda (2014) estimaram tarifas equivalentes para BNT aplicadas ao comércio de carne bovina (fresca e congelada, com osso ou desossada) entre Brasil e União Europeia, para o período de 2000 a 2010. Os resultados apontam, em geral, para tarifas equivalentes elevadas tanto para carnes frescas quanto para as congeladas no período analisado. Isso significa que o preço doméstico da UE e o preço mundial diferem, o que pode sugerir que o mercado europeu tem sido protegido não apenas por tarifas, mas também por medidas não tarifárias, como as exigências técnicas e sanitárias. As autoras observam também que, na medida em que a preferência do consumidor pelo produto europeu cresce em relação à carne brasileira, o efeito de medidas não tarifárias deixaria de existir, indicando mesmo uma "desproteção" para a carne doméstica em relação à importada (SBARAI e MIRANDA, 2014, p. 278, grifos no original).

Uma pesquisa da Asia-Pacific Economic Cooperation ${ }^{4}$ (APEC), com mais de 400 respondentes, procurou identificar os obstáculos mais pesados encontrados pelas empresas na agricultura e no comércio de alimentos na região da APEC, com foco específico na identificação das BNT mais notórias. A pesquisa tentou capturar a "voz do negócio", entrevistando uma ampla seleção de líderes empresariais da APEC, com atenção específica ao impacto das BNT na segurança alimentar (APEC, 2016). Os resultados mostram que 58\% dos entrevistados referiram obstáculos processuais e encargos administrativos como a razão mais prevalente para não entrar em novos mercados, e 60\% acreditam que o ambiente comercial aumentará em complexidade. Os autores também encontraram um desalinhamento do pensamento entre empresários e o governo no assunto das BNT. Enquanto metade dos membros do governo entrevistados acredita que as despesas que uma empresa incorre a fim de aderir aos regulamentos da indústria estão diminuindo e a outra

\footnotetext{
4 Fórum de 21 países-membros localizado no Círculo do Pacífico, que visa promover o livre comércio e a cooperação econômica em toda a região da Ásia-Pacífico. Fazem parte da APEC: Austrália, Brunei, Canadá, Chile, China, Indonésia, Japão, Coreia do Sul, Malásia, México, Nova Zelândia, Papua Nova Guiné, Peru, Filipinas, Rússia, Cingapura, Tailândia, Vietnã e Estados Unidos, além de Taiwan e Hong Kong.
} 
metade acredita que estão aumentando, $87 \%$ dos empresários acreditam que as despesas estão somente aumentando.

Além disso, 69\% dos membros do governo acreditam que as regulamentações são simples e transparentes. Em contrapartida, 80\% dos empresários consideram que as regulamentações são difíceis e complexas. Aos questionados sobre abertura comercial, 66\% do setor público acredita que o comércio já é aberto, enquanto $51 \%$ do setor privado crê que o ambiente comercial é fortemente protegido. Sobre as BNT, 75\% dos membros do governo acreditam que as mesmas são justas e consistentes. Por outro lado, 69\% dos empresários pensam que são aplicadas maneiras tendenciosas e discriminatórias.

Almeida (2012) estudou os efeitos das notificações aos acordos de medidas sanitárias e fitossanitárias (SPS) e de medidas técnicas (TBT) sobre o comércio internacional dos produtos agrícolas de maior destaque na pauta de exportação do Brasil, entre 1996 e 2010. A autora estimou equações de gravidade pelo método de seleção amostral com máxima verossimilhança, e os resultados mostram que as exigências direcionadas ao crescimento das informações aos consumidores favorecem positivamente o comércio da maioria dos produtos agrícolas em análise, como açúcar de cana, café, fumo, carne bovina e carne de frango. No entanto, não evidenciaram efeitos padronizados em relação às exigências ligadas diretamente à saúde humana e às medidas técnicas, o que significa que, de modo geral, eles foram ambíguos (ALMEIDA, 2012).

Estudo do IEDI (2014) analisou o impacto tanto de barreiras tarifárias quanto não tarifárias, na simulação de vários Acordos Preferenciais de Comércio (APC) para o Brasil, por meio do modelo de equilíbrio geral computável GTAP, com a versão 8 da base de dados. Os impactos das BNT foram estimados utilizando a metodologia do ECORYS, desenvolvida por Berden et al. (2009) para a Comissão Europeia. Os resultados mostraram que, em muitos deles, há um aumento expressivo das importações e exportações quando considerada a redução de $25 \%$ das BNT. No acordo com a União Europeia, o aumento das exportações para o mundo com a redução das BNT é quase duas vezes superior ao acordo considerando apenas as tarifas. No caso dos Estados Unidos, essa diferença chega a ser, aproximadamente, duas vezes e meia. De acordo com o estudo, isso ocorre porque as tarifas desses países já são bastante baixas.

Os trabalhos mencionados, em geral, apontam para o aumento da incidência das BNT, o que dificulta o comércio entre países. Ainda há poucos estudos na literatura brasileira que objetivam medir o impacto de BNT na economia, principalmente no âmbito multilateral, como mostra o Quadro 1. Esse trabalho pretende justamente preencher essa lacuna, ao fornecer uma estimativa sobre o peso das BNT sobre o comércio brasileiro. 
Quadro 1 - Quadro síntese dos trabalhos

\begin{tabular}{|c|c|c|c|}
\hline Autor(es) & Metodologia & Objetivos e simulações & Resultado \\
\hline $\begin{array}{l}\text { Arêdes e } \\
\text { Pereira } \\
(2009)\end{array}$ & $\begin{array}{l}\text { Modelo de } \\
\text { Equilíbrio Geral } \\
\text { Computável (EGC) } \\
\text { GTAP } \\
\text { Versão } 6.0\end{array}$ & $\begin{array}{l}\text { Avaliar os impactos da Rodada Doha } \\
\text { sobre o agronegócio, a economia e o } \\
\text { bem-estar no Brasil e no Mercosul. } \\
\text { Foram analisados três cenários de } \\
\text { corte total e parcial de tarifas. }\end{array}$ & $\begin{array}{l}\text { O setor agrícola do Brasil e do Mercosul } \\
\text { foi competitivo em todos os cenários, } \\
\text { elevando a produção e a exportação e } \\
\text { diminuindo a importação do setor. }\end{array}$ \\
\hline $\begin{array}{l}\text { Figueiredo } \\
\text { et al. } \\
(2010)\end{array}$ & $\begin{array}{l}\text { Modelo Aplicado de } \\
\text { Equilíbrio Geral } \\
\text { (MAEG) para a } \\
\text { economia dos EUA } \\
\text { e do Brasil }\end{array}$ & $\begin{array}{l}\text { Avaliar os impactos dos subsídios à } \\
\text { produção agrícola dos EUA - } \\
\text { concedidos por meio dos Loan } \\
\text { Deficiency Payments (LDP) - sobre o } \\
\text { crescimento do agronegócio } \\
\text { brasileiro. Foi simulada uma redução } \\
\text { de } 60 \% \text { na média anual dos LDP, } \\
\text { entre } 2002 \text { a } 2007 \text {. }\end{array}$ & $\begin{array}{l}\text { A redução dos subsídios agrícolas dos } \\
\text { EUA promoveria maior competitividade } \\
\text { das exportações brasileiras, propiciando } \\
\text { aumentos de produção e produtividade } \\
\text { e reduzindo os custos relativos do } \\
\text { capital e do trabalho na agricultura do } \\
\text { Brasil, criando oportunidades para o } \\
\text { crescimento do agronegócio. }\end{array}$ \\
\hline $\begin{array}{l}\text { Sbarai e } \\
\text { Miranda } \\
(2014)\end{array}$ & Método price-wedge & $\begin{array}{l}\text { Analisar os impactos das medidas } \\
\text { sanitárias e técnicas aplicadas pela } \\
\text { União Europeia sobre a exportação de } \\
\text { carne bovina brasileira, por meio da } \\
\text { obtenção de tarifas equivalentes. }\end{array}$ & $\begin{array}{l}\text { Em geral, observam-se tarifas } \\
\text { equivalentes elevadas, i.e., os preços } \\
\text { domésticos europeus e os preços } \\
\text { mundiais diferem, o que pode indicar } \\
\text { que o mercado da UE está sendo } \\
\text { protegido por medidas não tarifárias. }\end{array}$ \\
\hline $\begin{array}{l}\text { APEC } \\
(2016)\end{array}$ & $\begin{array}{l}\text { Entrevistas e análise } \\
\text { de dados sobre } \\
\text { múltiplas } \\
\text { perspectivas }\end{array}$ & $\begin{array}{l}\text { Identificar os impedimentos mais } \\
\text { onerosos encontrados pelas empresas } \\
\text { na agricultura e no comércio de } \\
\text { alimentos na região da APEC, com } \\
\text { um foco específico na identificação } \\
\text { das BNT mais notórias. }\end{array}$ & $\begin{array}{l}\text { As BNT estão aumentando em destaque } \\
\text { e complexidade em todas as economias } \\
\text { da APEC. Obstáculos processuais } \\
\text { frustram os negócios, mas as medidas } \\
\text { TBT e SPS são as mais onerosas. }\end{array}$ \\
\hline $\begin{array}{l}\text { Almeida } \\
(2012)\end{array}$ & $\begin{array}{l}\text { Modelo } \\
\text { Gravitacional }\end{array}$ & $\begin{array}{l}\text { Identificar os efeitos que os diferentes } \\
\text { objetivos contidos nas notificações } \\
\text { aplicadas aos acordos TBT e SPS da } \\
\text { OMC tiveram sobre o comércio } \\
\text { internacional de diferentes produtos } \\
\text { agroalimentares, entre } 1996 \text { e } 2010 .\end{array}$ & $\begin{array}{l}\text { As notificações com objetivos de } \\
\text { aumento de informações aos } \\
\text { consumidores contribuíram para o } \\
\text { aumento do comércio da maioria dos } \\
\text { produtos selecionados. }\end{array}$ \\
\hline $\begin{array}{l}\text { IEDI } \\
(2014)\end{array}$ & $\begin{array}{l}\text { Modelo de } \\
\text { Equilíbrio Geral } \\
\text { Computável (EGC) } \\
\text { e GTAP (Versão } 8.0 \\
\text { da base de dados) }\end{array}$ & $\begin{array}{l}\text { Demonstrar a importância das } \\
\text { barreiras não tarifárias para o acesso } \\
\text { a mercados do Brasil em seus } \\
\text { eventuais parceiros preferenciais, } \\
\text { simulando os impactos para a } \\
\text { economia brasileira de uma série de } \\
\text { APC. }\end{array}$ & $\begin{array}{l}\text { Em diversos acordos, há um aumento } \\
\text { expressivo das importações e } \\
\text { exportações quando considerada a } \\
\text { redução de } 25 \% \text { das BNT. No acordo } \\
\text { com a UE, o aumento das exportações } \\
\text { para o mundo com a redução das BNT } \\
\text { é quase duas vezes superior ao acordo } \\
\text { considerando apenas as tarifas. }\end{array}$ \\
\hline
\end{tabular}

Fonte: Elaboração própria.

\section{METODOLOGIA}

Um modelo de equilíbrio geral computável pode ser determinado como "uma representação numérica das condições de equilíbrio de uma economia, promovidas por agentes econômicos representados por equações comportamentais" (FOCHEZATTO, 2005, p. 114). De acordo com o autor, seu propósito é tornar a concepção teórica de 
equilíbrio geral walrasiano, formalizada nos anos 1950 por Kenneth Arrow, Gerard Debreu e outros, em modelos aplicados à economia real. Nos últimos 20 anos, os modelos de equilíbrio geral computável se tornaram bastante populares. É possível atribuir isso ao fato de que eles possibilitam a modelagem, em maior ou menor grau, da complexa interdependência entre as instituições e os agentes que compõem a economia (FOCHEZATTO, 2005).

De acordo com Fochezatto (2005), os modelos de equilíbrio geral computável são instrumentos propícios para analisar mudanças de políticas econômicas, que tendem a causar efeitos complexos e de difícil identificação. Em relação às principais aplicações dos modelos, Fochezatto (2005) cita a análise de temas relacionados ao comércio internacional; à distribuição de renda, aos choques externos; às políticas tributárias e fiscais; e à escolha de estratégias de desenvolvimento. Porém, o autor também destaca que, apesar da popularidade da modelagem EGC, ainda existem dificuldades para a construção desses modelos. Uma delas é a falta de disponibilidade de informações necessárias para a calibragem dos seus parâmetros, visto que as fontes de informações existentes normalmente estão defasadas e incompatíveis entre si, o que torna indispensável um processo de ajustamento para a obtenção da consistência necessária. Outra dificuldade é conhecer o real comportamento dos atores econômicos e modelálos de forma correta, dado que pode haver suposições equivocadas quanto às preferências, tecnologia e regras comportamentais.

Segundo Santos, Vieira e Reis, "[a principal fonte de dados para calibrar um modelo aplicado de equilíbrio geral provém de uma Matriz de Contabilidade Social (MCS), a partir da qual se inicia todo o processo de construção dos modelos aplicados de equilíbrio geral" (2007, p. 458). Para os autores, com os dados contidos na MCS, começa o procedimento de calibração, no qual são especificadas as equações comportamentais e identidades contábeis de cada agente inserido no modelo, juntamente com seus parâmetros; depois, são aplicados choques nas variáveis exógenas, obtendo-se, de imediato, um novo equilíbrio, e, por fim, é feita a análise comparativa entre os equilíbrios inicial e final.

\subsection{O MODELO GTAP}

O modelo GTAP padrão é um modelo de equilíbrio geral multirregional e multissetorial, com concorrência perfeita e retornos constantes de escala. A estrutura produtiva do GTAP assume três níveis de especificação, e pode ser melhor compreendida por meio da Figura 1. No topo, a função de produção assume substitutibilidade zero entre os fatores primários de produção e os insumos intermediários (tecnologia de Leontief). 
Assim, o mix ótimo de fatores primários é independente dos preços dos insumos intermediários, enquanto o mix ótimo de insumos intermediários não varia com o preço dos fatores primários. O segundo nível envolve uma elasticidade de substituição constante tanto entre os insumos intermediários como entre os fatores de produção $(\sigma V A)$. Assume-se que os insumos importados são diferenciados por origem $(\sigma M)$, assim como os insumos domésticos são discriminados em relação aos importados $(\sigma D)$. Isso é, as firmas inicialmente determinam o mix ótimo de insumos domésticos e importados e somente depois decidem a respeito da origem das importações (hipótese de Armington). O nível mais baixo do ninho também assume uma elasticidade de substituição constante entre insumos importados de diferentes origens (FEIJÓ e ALVIM, 2010, p. 4-5).

\section{Figura 1 - Estrutura produtiva do GTAP}

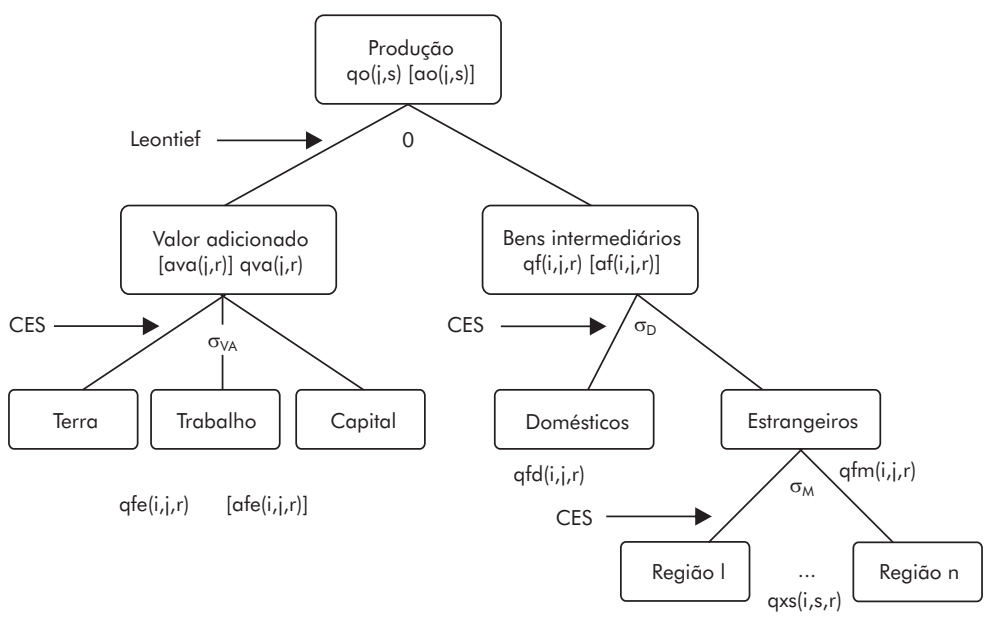

Fonte: Herthel (1997, apud FEIJÓ e ALVIM, 2010).

\subsection{AGREGAÇÕES E CENÁRIOS}

Para mensurar o impacto da redução multilateral de barreiras tarifárias e não tarifárias, as agregações regionais e setoriais foram realizadas conforme o Quadro 2. A agregação regional foi feita com base nos principais parceiros comerciais do Brasil, além de serem economias em que o setor primário é relevante. Já agregação setorial foi criada para ver o impacto de reduções tarifárias e não tarifárias em setores específicos que interessam ao país. Pelo foco do trabalho estar no setor primário, e também o da Rodada Doha, desagregou-se o mesmo em grãos, pecuária e extração mineral. O restante dos setores foi agregado por intensidade tecnológica, conforme classificação 
da OCDE, que utiliza a intensidade de P\&D como o mais importante indicador para classificar os setores industriais de acordo com a sua intensidade tecnológica (FURTADO e CARVALHO, 2005).

\section{Quadro 2 - Agregações regionais e setoriais}

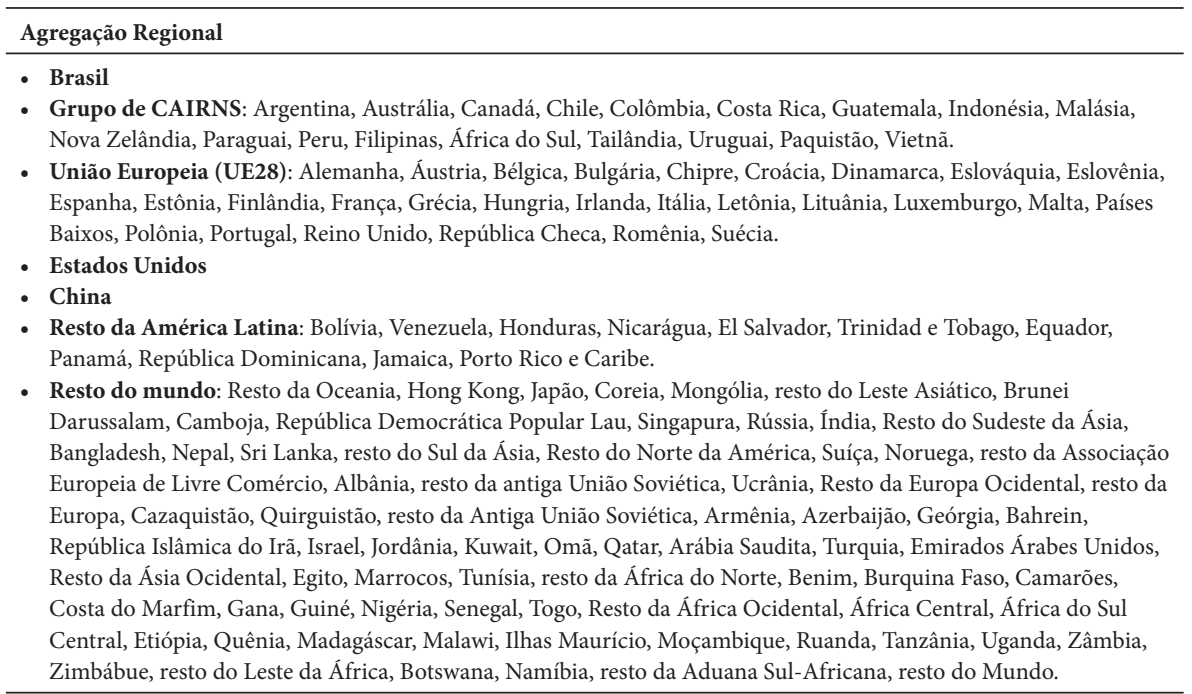

\section{Agregação Setorial}

- Grãos e outras culturas: arroz, trigo, cereais, legumes, frutas, nozes, sementes oleaginosas, cana-de-açúcar, açúcar de beterraba, fibras vegetais, outras culturas.

- Pecuária: gado, ovelha, cabras, cavalos, produtos de origem animal, leite, lã, casulo de seda, carne - bovinos, ovinos, caprinos, equinos, produtos de carne.

- Extração mineral: silvicultura, pesca, carvão, petróleo, gás, minerais.

- Agroindústria: óleos vegetais e gorduras, produtos lácteos, arroz processado, açúcar, produtos alimentícios, bebidas e produtos do tabaco.

- Baixa tecnologia: têxteis, vestuário, produtos de couro, produtos de madeira, produtos de papel, publicação.

- Média-baixa tecnologia: petróleo, carvão produtos, produtos minerais, metais ferrosos, metais, produtos metálicos.

- Média-alta tecnologia: produtos químicos, borracha, plástico, automóveis e peças.

- Alta tecnologia: equipamentos de transporte, equipamentos eletrônicos, máquinas e equipamentos, manufaturas.

- Serviços: eletricidade, fabricação e distribuição de gás, água, construção, comércio, transportes, transporte marítimo, transporte aéreo, comunicação, serviços financeiros, seguros, negócios, serviços, recreação e outros serviços, administração pública, defesa, saúde, educação, habitações.

Fonte: Elaboração própria com base no GTAP (2011).

Em relação aos cenários simulados, foram incluídos quatro na pesquisa, descritos no Quadro 3. Vários estudos de simulações tarifárias, tanto no âmbito multilateral como de formação de APC, incorporam reduções parciais e totais de tarifas, como Arêdes e Pereira (2009) e Sampaio e Sampaio (2009). Quanto às BNT, o estudo do IEDI (2014) também incorporou somente reduções parciais, visto que essas barreiras são geralmente introduzidas por algum propósito, como saúde humana, animal e vegetal, o que dificulta a total remoção destas. 


\section{Quadro 3 - Cenários simulados}

\begin{tabular}{ll}
\hline Cenário 1 & Cenários \\
Cenário 2 & Redução tarifária multilateral de $50 \%$ \\
Cenário 3 & Redução tarifária multilateral de $100 \%$ \\
Cenário 4 & Redução multilateral de barreiras não tarifária multilateral de $100 \%$ + redução de BNT de $50 \%$ \\
\hline
\end{tabular}

Fonte: Elaboração própria.

O software GTAP possui em sua base de dados as tarifas de importação aplicadas pelos países para o ano de 2011. Sendo assim, foi dado um choque de 50\% e 100\%, multilateralmente, nessas tarifas. Nas rodadas de negociações do GATT e da OMC, os países (em especial os desenvolvidos) foram gradativamente reduzindo suas tarifas de importação. Com isso, as barreiras não tarifárias (BNT) começaram a ser usadas com mais frequência. Em razão da existência das BNT, uma parcela do valor de exortação "derreteria" (custo iceberg), no caminho do país exportador ao importador, o equivalente a uma perda de eficiência do exportador. Em termos de modelagem no GTAP, reduzir as BNT implica na redução dos custos do comércio, ou seja, um aumento da eficiência do país exportador. Isso é feito nos cenários 3 e 4, onde são incorporadas as reduções de barreiras não tarifárias por meio da variável "ams" do GTAP, que simula a melhoria da eficiência, e, sendo assim, reduz o preço efetivo das importações de bens e serviços.

Como explicam Fugazza e Maur (2008), por um lado, um choque na variável “ams” reduz o preço das importações, levando a um aumento da demanda por esses bens em detrimento dos domésticos. Por outro lado, indica que o ganho de eficiência por trás do choque aumenta o conteúdo de produção real de cada unidade exportada. Isso implica que são necessárias menos exportações para atender à demanda do país importador. O efeito médio destas pode ser verificado na Tabela 1.

Tabela 1 - Efeito médio das barreiras não tarifárias

\begin{tabular}{lcc}
\hline & Setor Agrícola & Setor Industrial \\
\hline Brasil & $0,20 \%$ & $20,60 \%$ \\
Cairns & $0,12 \%$ & $14,51 \%$ \\
União Europeia & $0,80 \%$ & $15,40 \%$ \\
Estados Unidos & $0,20 \%$ & $10,80 \%$ \\
China & $0,00 \%$ & $7,60 \%$ \\
Resto AL & $0,02 \%$ & $8,18 \%$ \\
Resto Mundo & $0,01 \%$ & $12,94 \%$ \\
\hline
\end{tabular}

Fonte: Elaboração própria com base nos dados de Kee et al. (2009). 
Os parâmetros acima foram reduzidos em $50 \%$ e foram obtidos no estudo de Kee et al. (2009). Os autores estimaram uma regressão econométrica com o objetivo de fornecer uma medida de restrição comercial bem fundamentada na teoria do comércio e que contabiliza diferentes formas de proteção comercial. Kee et al. (2009) incorporaram no modelo duas variáveis BNT: a primeira incluiu medidas de controle de preços, restrições quantitativas, medidas monopolísticas e regulações técnicas; a segunda variável BNT foi de apoio doméstico à agricultura. Os valores das agregações regionais presentes na Tabela 1 foram encontrados por meio da média simples de cada país. Destaca-se que não há dados no estudo de Kee et al. (2009) para Paquistão e Vietnã, que fazem parte do grupo de CAIRNS, e para Equador, Panamá, República Dominicana, Jamaica, Porto Rico e Caribe, incluídos na agregação Resto da América Latina. Assim, a média dos parâmetros foi feita com base nos países em que os dados foram encontrados.

A base de dados utilizada neste estudo será a 9a versão do GTAP, a versão mais recente durante a realização da pesquisa, que apresenta matrizes insumo produtos de 140 países/regiões com 57 atividades econômicas, correspondente a economia mundial no ano de 2011. Os dados originais do GTAP serão agregados em seis regiões e 11 mercadorias diferentes

\section{RESULTADOS E DISCUSSÃO}

Esta seção apresenta os resultados das simulações feitas no estudo para cada setor e região. Serão retratados os dados das variações do comércio internacional e do bemestar. A Tabela 2 mostra a tarifa média de importação que cada região aplica para seus parceiros comerciais, com base no GTAP (2011), antes dos choques. Após os choques, espera-se que os setores inicialmente mais protegidos sejam os que apresentam uma maior variação do comércio.

O Brasil apresenta um grau de protecionismo maior nos setores industriais, em alguns deles significativamente mais alto do que as demais regiões. Esse é o caso, por exemplo, dos produtos de baixa intensidade tecnológica. Já o setor de extração mineral é o de menor tarifa média. No grupo de CAIRNS, o setor de pecuária é o mais protegido, seguido da agroindústria. Assim como no Brasil, o setor de extração mineral é o que possui a menor tarifa. No caso americano e da União Europeia, verifica-se que, de modo geral, as tarifas são relativamente menores quando comparadas com as outras regiões incluídas no estudo. A maior tarifa dos EUA é sobre os produtos de baixa intensidade tecnológica, e, na UE, é sobre a pecuária. As tarifas chinesas são mais elevadas para a agroindústria e a pecuária, e as menores tarifas são as incidentes sobre o setor de extração mineral. Já na América Latina, o setor da agroindústria é o mais protegido, e o de extração mineral é o de menor tarifa média de importação. 
Tabela 2 - Tarifa média inicial de importação das regiões para cada setor

\begin{tabular}{lccccccc}
\hline & Brasil & CAIRNS & EUA & China & UE & R. AL & R. Mundo \\
\hline Grãos & 6,30 & 5,44 & 1,21 & 4,39 & 2,47 & 6,38 & 20,65 \\
Pecuária & 3,42 & 10,59 & 1,30 & 11,62 & 15,06 & 7,48 & 17,21 \\
Extração Min. & 0,97 & 0,37 & 0,11 & 0,29 & 0,07 & 2,41 & 1,65 \\
Agroindústria & 9,42 & 8,11 & 2,72 & 18,61 & 7,97 & 16,24 & 15,26 \\
M. B. I. & 17,28 & 5,26 & 4,33 & 3,35 & 2,91 & 7,76 & 6,53 \\
M. M. B. I. & 4,20 & 2,17 & 1,11 & 3,03 & 0,93 & 5,10 & 3,13 \\
M. M. A. I. & 7,88 & 4,13 & 0,91 & 7,74 & 1,58 & 6,39 & 4,85 \\
M. A. I. & 10,65 & 2,02 & 0,39 & 5,18 & 0,76 & 5,60 & 2,95 \\
Serviços & 0,00 & 0,00 & 0,00 & 0,00 & 0,00 & 0,00 & 0,00 \\
\hline
\end{tabular}

Notas: M.B.I. - manufaturas de baixa Intensidade tecnológica; M. M. B. I. - manufaturas de média baixa intensidade tecnológica; M. M. A. I. - manufaturas de média alta intensidade tecnológica; e M. A. I. - manufaturas de alta intensidade tecnológica.

Fonte: Elaboração própria a partir dos dados do GTAP.

\subsection{COMÉRCIO INTERNACIONAL}

Pode-se observar na Tabela 3 que, no cenário 1, o maior aumento do volume de exportações brasileiras foi exatamente no setor de pecuária, seguido de agroindústria, fortemente protegidos em mercados importantes para o Brasil, como CAIRNS, China e UE. O setor com maior tarifa média no grupo de CAIRNS era o de pecuária. O setor mais protegido nos Estados Unidos é o de baixa intensidade tecnológica, seguido da agroindústria. $\mathrm{O}$ maior aumento das exportações brasileiras foi na agroindústria, seguido do setor de média alta intensidade tecnológica. Porém, cabe destacar que, como os Estados Unidos já possuíam tarifa de importação relativamente baixas antes dos choques, não houve um aumento significativo do volume de exportação brasileira. Para a China, o setor exportador mais beneficiado seria a agroindústria e, depois, as manufaturas de alta intensidade tecnológica.

Em relação à União Europeia, o setor de pecuária também possuía a maior tarifa média (16,98\%), e as exportações brasileiras cresceram justamente mais nesse setor. É possível notar que, em termos percentuais, o maior aumento de exportações do Brasil, em comparação com todos os parceiros comerciais e todos os setores, foi de pecuária para a UE (144,57\%). No resto da América Latina, observou-se significativo aumento de exportações brasileiras no setor agroindustrial, que, mais uma vez, era o de maior tarifa de importação. Houve queda de exportação em todo o setor primário, o que pode indicar que, com a redução tarifária, torna-se mais vantajoso para o Brasil exportar o produto processado no lugar do in natura. Quando analisado o total por setor, percebe-se que a pecuária e a agroindústria seriam os maiores beneficiados. 
Tabela 3 - Desempenho das exportações brasileiras no Cenário 1 (em \%)

\begin{tabular}{lccccccc}
\hline & CAIRNS & EUA & China & UE & R. AL & R. Mundo & Total \\
\hline Grãos & 18,2 & 2,29 & 4,28 & $-3,85$ & $-4,2$ & 28,48 & 45,2 \\
Pecuária & 24,99 & $-1,63$ & $-8,67$ & 144,57 & $-5,16$ & $-5,4$ & 148,7 \\
Extração Min. & $-0,95$ & 1,53 & 0,63 & 1,92 & $-2,44$ & 4,51 & 5,2 \\
Agroindústria & $-3,88$ & 6,62 & 62,17 & 35,86 & 41,32 & 1,94 & 144,03 \\
M. B. I. & $-8,5$ & $-7,1$ & 3,92 & 1,17 & $-3,41$ & 3,65 & $-10,27$ \\
M. M. B. I. & $-4,67$ & 0,7 & 0,17 & 2,43 & $-2,36$ & $-0,2$ & $-3,93$ \\
M. M. A. I. & $-7,36$ & 2,93 & 3,49 & 4,89 & $-8,11$ & 11,3 & 7,14 \\
M. A. I. & $-1,97$ & 1,93 & 20,93 & 2,25 & $-9,85$ & 13,14 & 26,43 \\
Serviços & $-0,38$ & $-0,87$ & 1,36 & $-0,48$ & $-1,8$ & 0,11 & $-2,06$ \\
\hline
\end{tabular}

Nota: M.B.I. - manufaturas de baixa Intensidade tecnológica; M. M. B. I. - manufaturas de média baixa intensidade tecnológica; M. M. A. I. - manufaturas de média alta intensidade tecnológica; e M. A. I. - manufaturas de alta intensidade tecnológica.

Fonte: Elaboração própria a partir dos dados do GTAP.

Tabela 4 - Desempenho das exportações brasileiras no Cenário 2 (em \%)

\begin{tabular}{lccccccc}
\hline & CAIRNS & EUA & China & UE & R.AL & R. Mundo & Total \\
\hline Grãos & 37,35 & 2,08 & 6,71 & $-11,38$ & $-10,81$ & 64 & 87,95 \\
Pecuária & 46,43 & $-7,64$ & $-22,94$ & 491,5 & $-15,59$ & $-21,04$ & 470,72 \\
Extração Min. & $-2,44$ & 2,54 & 0,76 & 3,63 & $-5,37$ & 8,8 & 7,92 \\
Agroindústria & $-10,17$ & 11,2 & 176,64 & 84,2 & 106,2 & 0,57 & 368,64 \\
M. B. I. & $-18,91$ & $-15,9$ & 5,98 & $-0,48$ & $-9,76$ & 4,39 & $-34,68$ \\
M. M. B. I. & $-10,86$ & $-0,19$ & $-1,62$ & 3,13 & $-6,52$ & $-2,21$ & $-18,27$ \\
M. M. A. I. & $-16,83$ & 3,73 & 3,94 & 7,67 & $-18,49$ & 21,38 & 1,4 \\
M. A. I. & $-6,61$ & 1,09 & 42,58 & 1,65 & $-21,59$ & 24,69 & 41,81 \\
Serviços & $-2,69$ & $-3,67$ & 0,89 & $-2,98$ & $-5,56$ & $-1,88$ & $-15,89$ \\
\hline
\end{tabular}

Nota: M.B.I. - manufaturas de baixa Intensidade tecnológica; M. M. B. I. - manufaturas de média baixa intensidade tecnológica; M. M. A. I. - manufaturas de média alta intensidade tecnológica; e M. A. I. - manufaturas de alta intensidade tecnológica.

Fonte: Elaboração própria a partir dos dados do GTAP.

No segundo cenário, o impacto do volume de exportações brasileiras segue o padrão do cenário 1 , mas a magnitude das variações é maior (Tabela 4). O setor de pecuária é o mais beneficiado, com um aumento maior para o grupo de CAIRNS e UE, chegando a 46,43\% e 491,5\%, respectivamente. Para os EUA, resto da América Latina e China, a agroindústria lidera o crescimento das exportações, com aumentos de $14,55 \%, 106,2 \%$ e $176,64 \%$, respectivamente. Também houve crescimento 
significativo de exportações de produtos agroindustriais para a União Europeia $(84,2 \%)$. Novamente, quando se examina o total por setor, os maiores aumentos de exportação ocorreriam na pecuária e na agroindústria.

Tabela 5 - Desempenho das exportações brasileiras no Cenário 3 (em \%)

\begin{tabular}{|c|c|c|c|c|c|c|c|}
\hline & CAIRNS & EUA & China & UE & R. AL & R. Mundo & Total \\
\hline Grãos & 3,52 & 2,92 & 2,08 & 5,17 & 2,61 & 3,06 & 19,36 \\
\hline Pecuária & 6,19 & 3,91 & 5,62 & 11,48 & 1,35 & 4,89 & 33,44 \\
\hline Extração Min. & $-2,19$ & 1,13 & 2,54 & $-3,61$ & 1,52 & $-1,56$ & $-2,17$ \\
\hline Agroindústria & 10,46 & 6,83 & 6,09 & 12,64 & 4,78 & 8,08 & 48,88 \\
\hline M. B. I. & 16,23 & 12,13 & 14,51 & 19,57 & 8,41 & 13,38 & 84,23 \\
\hline M. M. B. I. & 9,04 & 9,47 & 10,08 & 10,54 & 5,6 & 10,1 & 54,83 \\
\hline M. M. A. I. & 12,02 & 14,41 & 14,15 & 12,55 & 9,43 & 13,44 & 76 \\
\hline M. A. I. & 9,76 & 14,07 & 14,48 & 18,47 & 8,41 & 14,15 & 79,34 \\
\hline Serviços & 5,75 & 2,02 & 1,33 & 7,54 & 2,53 & 3,45 & 22,62 \\
\hline
\end{tabular}

Nota: M.B.I. - manufaturas de baixa Intensidade tecnológica; M. M. B. I. - manufaturas de média baixa intensidade tecnológica; M. M. A. I. - manufaturas de média alta intensidade tecnológica; e M. A. I. - manufaturas de alta intensidade tecnológica.

Fonte: Elaboração própria a partir dos dados do GTAP.

Quando se analisam os resultados da simulação de barreiras não tarifárias, percebe-se uma mudança substancial na pauta exportadora brasileira, em relação aos cenários que incorporavam somente barreiras tarifárias. Os setores industriais seriam mais beneficiados, e apenas o setor de extração mineral reduziria suas exportações para o grupo de CAIRNS, União Europeia e resto do mudo. Todos os outros setores aumentariam o volume exportado para todas as regiões. No caso do grupo de CAIRNS, o maior aumento das exportações brasileiras é no setor de baixa intensidade tecnológica, seguido do de média alta intensidade. O setor de média alta intensidade tecnológica lideraria as exportações para os EUA, seguido do de alta intensidade tecnológica. Para a China, haveria maior aumento de exportações no setor de baixa e alta intensidade tecnológica. Esses mesmos setores também seriam os mais beneficiados na UE e resto da América Latina. No total de exportações por setor, quem mais se beneficiaria seria o setor de baixa intensidade tecnológica, seguido pelas manufaturas de alta intensidade tecnológica. Os resultados vêm ao encontro de estudos como o do IEDI (2014), que mostra que, na simulação de diversos acordos preferenciais, há um aumento expressivo das importações e exportações quando considerada a redução de $25 \%$ das BNT. No acordo com a UE, o aumento das exportações para o mundo com a 
redução das BNT seria quase duas vezes superior ao que produziria o acordo considerando apenas as tarifas. No acordo com os EUA, essa diferença chegaria a ser, aproximadamente, duas vezes e meia. Isso ocorre porque as tarifas desses países já são bastante baixas. Assim, a redução das BNT seria muito mais expressiva para o acesso a mercados que a eliminação de tarifas.

Tabela 6 - Desempenho das exportações brasileiras no Cenário 4 (em \%)

\begin{tabular}{|c|c|c|c|c|c|c|c|}
\hline & CAIRNS & EUA & China & UE & R. AL & R. Mundo & Total \\
\hline Grãos & 41,25 & 4,59 & 8,81 & $-7,98$ & $-8,81$ & 67,43 & 105,29 \\
\hline Pecuária & 52,18 & $-5,12$ & $-18,83$ & 540,76 & $-15,18$ & $-17,54$ & 536,27 \\
\hline Extração Min. & $-4,55$ & 3,73 & 3,3 & $-0,04$ & $-3,86$ & 7,18 & 5,76 \\
\hline Agroindústria & $-1,54$ & 18,16 & 191,74 & 105,21 & 114,97 & 7,86 & 436,4 \\
\hline M. B. I. & $-5,98$ & $-5,51$ & 22,35 & 18,14 & $-1,71$ & 18,23 & 45,52 \\
\hline M. M. B. I. & $-3,1$ & 8,96 & 7,99 & 13,69 & $-1,52$ & 7,35 & 33,37 \\
\hline M. M. A. I. & $-7,2$ & 18,66 & 18,3 & 20,91 & $-10,95$ & 37,41 & 77,13 \\
\hline M. A. I. & 2,44 & 15,58 & 63,08 & 20,15 & $-15,03$ & 42,27 & 128,49 \\
\hline Serviços & 2,37 & $-2,08$ & 1,88 & 3,67 & $-3,44$ & 1,13 & 3,53 \\
\hline
\end{tabular}

Nota: M.B.I. - manufaturas de baixa Intensidade tecnológica; M. M. B. I. - manufaturas de média baixa intensidade tecnológica; M. M. A. I. - manufaturas de média alta intensidade tecnológica; e M. A. I. - manufaturas de alta intensidade tecnológica.

Fonte: Elaboração própria a partir dos dados do GTAP.

O último cenário, que incorpora tanto barreiras tarifárias quanto não tarifárias, é o que mais aumenta o volume de exportação de oito setores, dos onze incluídos no estudo, comparativamente aos três cenários anteriores. O setor de pecuária, seguido do agroindustrial, é, novamente, o que lidera o aumento das exportações. Destaque para o expressivo crescimento das exportações pecuárias para a União Europeia, de 540,76\%, e da agroindústria para a China (191,74\%), resto da América Latina $(114,97 \%)$ e UE (105,21\%). Quando analisado o total de exportações por setor, nota-se o aumento considerável do setor de pecuária e da agroindústria, seguido pelas manufaturas de alta intensidade tecnológica e pelo setor de grãos.

Nesse sentido, verifica-se que o perfil da liberalização afetaria diferentemente as exportações brasileiras. A liberalização tarifária beneficiaria principalmente os setores primários e agroindustriais, que, como já mencionado, ainda permanecem com as tarifas mais elevadas comparativamente aos setores industriais. Já a redução multilateral das BNT afetaria especialmente os setores industriais, de maior conteúdo tecnológico. Portanto, as negociações brasileiras na atual Rodada Doha devem levar em consideração esses aspectos. 


\subsection{ANÁLISE DO BEM-ESTAR}

Nos modelos de competição perfeita, os ganhos de bem-estar dos países/regiões que participam do processo de liberalização comercial advêm, principalmente, da melhor alocação dos recursos e/ou melhoria nos termos de troca. Quando se incorporam barreiras não tarifárias no modelo, também há ganhos referentes aos efeitos tecnológicos, pela forma como eles são modelados. Espera-se que os efeitos da eficiência tecnológica gerem ganhos positivos de modo geral, visto que os choques de eficiência reduzem o preço das importações, levando a um aumento da demanda à custa dos bens domésticos. Também, ganhos de eficiência aumentam a produção real de cada unidade única exportada. Isso implica que são necessárias menos exportações para atender à demanda do país importador. Como no GTAP esse ganho de eficiência se aplica de forma não discriminatória a todas as importações, não há efeitos de desvio de comércio. Isso deve resultar em efeitos de bem-estar positivos inequívocos para todos os países (FUGAZZA e MAUR, 2008). Nas Tabelas 7, 8, 9 e 10, são apresentados os resultados para os cenários simulados. Destaca-se que o Brasil seria beneficiado em todos os cenários e os ganhos se elevam na medida que a liberalização se aprofunda.

Tabela 7 - Desempenho do bem-estar no Cenário 1 (em US\$ milhões)

\begin{tabular}{lcccc}
\hline & Efeito Alocativo & Termos de Troca & Efeito I-S & Total \\
\hline Brasil & 2.733 & 451,00 & 60,80 & 3.245 \\
CAIRNS & 5.721 & -1.023 & 420,00 & 5.118 \\
EUA & 346,00 & -2.684 & -2.338 & -4.676 \\
China & 19.182 & 9.812 & $-343,00$ & 28.650 \\
EU_28 & 7.821 & -1.312 & 343,00 & 6.852 \\
Resto da AL & 1.232 & -1.099 & $-200,00$ & $-67,30$ \\
Resto do Mundo & 28.252 & -4.191 & 2.056 & 26.117 \\
Total & 65.286 & $-44,70$ & $-1,50$ & 65.239 \\
\hline
\end{tabular}

Fonte: Elaboração própria a partir dos dados do GTAP.

Verifica-se que o maior beneficiado no cenário de redução parcial das tarifas de importação seria a China, com ganhos de bem-estar de US\$28,650 bilhões, seguida do resto do Mundo, com ganhos de US\$26,117 bilhões. O Brasil obteria ganhos da ordem de US\$ 3,245 bilhões, advindos principalmente dos efeitos alocativos. A União Europeia também seria beneficiada, em US\$ 6,852 bilhões. Os Estados Unidos, por sua vez, seriam os maiores prejudicados, com perdas de US\$ 4,676 bilhões, seguidos pelo resto da América Latina (US\$67,3 milhões). Os ganhos mundiais totais chegariam a mais de US\$ 65 bilhões. 
Tabela 8 - Decomposição do bem-estar no Cenário 2 (em US\$ milhões)

\begin{tabular}{lcccc}
\hline & Efeito Alocativo & Termos de Troca & Efeito I-S & Total \\
\hline Brasil & 4.288 & 2.342 & 81,40 & 6.711 \\
CAIRNS & 8.673 & -1.121 & 790,00 & 8.342 \\
EUA & $-197,00$ & -3.430 & -4.580 & -8.207 \\
China & 36.108 & 20.853 & $-821,00$ & 56.140 \\
EU_28 & 13.375 & -3.612 & 629,00 & 10.392 \\
Resto da AL & 1.837 & -2.377 & $-429,00$ & $-969,00$ \\
Resto do Mundo & 46.506 & -12.854 & 4.326 & 37.979 \\
Total & 110.590 & $-199,00$ & $-3,29$ & 110.388 \\
\hline
\end{tabular}

Fonte: Elaboração própria a partir dos dados do GTAP.

No segundo cenário, de liberalização multilateral tarifária total, os ganhos e perdas de bem-estar se intensificam. O maior também seria a China, com ganhos de US\$ 56,140 bilhões. As perdas dos Estados Unidos somariam US\$ 8,207 bilhões. O Brasil seria beneficiado em US\$ 6,711 bilhões, principalmente em decorrência, novamente, dos efeitos alocativos. Os ganhos da União Europeia somariam US\$10,392 bilhões. Quanto ao resto da América Latina, ocorre uma piora do bem-estar em relação ao primeiro cenário, e as perdas se intensificam em US\$ 969 milhões. Analisando o total, haveria ganhos mundiais de mais de US\$ 110 bilhões.

Tabela 9 - Decomposição do bem-estar no Cenário 3 (em US\$ milhões)

\begin{tabular}{lccccc}
\hline & E. Alocativo & E. Tecnológico & T. de Troca & Efeito I-S & Total \\
\hline Brasil & 4.916 & 23.099 & -1.679 & 73,50 & 26.410 \\
CAIRNS & 16.236 & 122.903 & 3.926 & 194,00 & 143.259 \\
EUA & 6.839 & 104.228 & -6.739 & -7.029 & 97.299 \\
China & 14.730 & 42.529 & -1.680 & 1.687 & 57.265 \\
EU_28 & 38.527 & 364.986 & 31.235 & 938,00 & 435.687 \\
R. AL & 932,00 & 8.437 & $-668,00$ & $-112,00$ & 8.589 \\
R.Mundo & 22.816 & 271.249 & -24.580 & 4.231 & 273.715 \\
Total & 104.996 & 937.431 & $-186,00$ & $-17,50$ & 1.042 .223 \\
\hline
\end{tabular}

Fonte: Elaboração própria a partir dos dados do GTAP.

O terceiro cenário, que simula o efeito da redução das barreiras não tarifárias em $50 \%$, incorpora na decomposição do bem-estar o efeito tecnológico (Tabela 9). Sendo assim, os maiores ganhos das regiões estão concentrados nesse componente. Observa-se que todas as regiões seriam beneficiadas e, em maior grau, quando em comparação com as reduções tarifárias. A União Europeia seria a mais favorecida (US\$ 435,687 bilhões), seguida do Resto do Mundo (US\$ 273,715 bilhões). Em relação ao Brasil, os ganhos 
decorrentes de uma redução de BNT seriam mais de três vezes maiores (US\$ 26,410 bilhões) em relação aos obtidos com uma liberalização tarifária total. Destaca-se que os Estados Unidos também obteriam ganhos expressivos (US\$ 97,299 bilhões), ao contrário do que foi verificado nos dois cenários anteriores. Ainda, os ganhos totais seriam mais de nove vezes superiores aos do cenário 2, superando US\$ 1 trilhão.

Os resultados deste estudo vêm ao encontro de outros trabalhos da literatura, que também verificaram maior ganho de bem-estar para as regiões com redução de BNT. Fugazza e Maur (2008) constataram que as simulações que utilizam efeitos de eficiência geram efeitos benéficos positivos para todas as regiões. Os autores acreditam que, em termos de implicações políticas, este poderia ser um resultado extremamente interessante, porque significa que a liberalização multilateral, que poderia assumir a forma de um reconhecimento mútuo das medidas técnicas, traria ganhos para todos os países envolvidos.

Tabela 10 - Decomposição do bem-estar no Cenário 4 (em US\$ milhões)

\begin{tabular}{lccccc}
\hline & E. Alocativo & E. Tecnológico & T. de Troca & Efeito I-S & Total \\
\hline Brasil & 8.323 & 24.436 & 1.144 & $-41,90$ & 33.861 \\
CAIRNS & 23.096 & 124.331 & 2.974 & 1.013 & 151.414 \\
EUA & 5.721 & 104.958 & -10.239 & -11.261 & 89.178 \\
China & 50.695 & 45.056 & 20.412 & 695,00 & 116.858 \\
EU_28 & 49.888 & 366.572 & 25.868 & 1.435 & 443.763 \\
R. da AL & 2.594 & 8.631 & -2.963 & $-491,00$ & 7.771 \\
R. do Mundo & 64.208 & 278.501 & -37.563 & 8.593 & 313.739 \\
Total & 204.525 & 952.484 & $-367,00$ & $-57,20$ & 1.156 .586 \\
\hline
\end{tabular}

Fonte: Elaboração própria a partir dos dados do GTAP.

Para o Brasil, grupo de CAIRNS, União Europeia e China o melhor cenário seria o 4 (Tabela 10). A redução tarifária total combinada com redução de $50 \%$ de barreiras não tarifárias traria ganhos, respectivamente, de US\$ 33,861 bilhões, US\$ 151,414 bilhões, US\$ 443,763 bilhões e US\$ 116,858 bilhões. Os Estados Unidos também seriam beneficiados (US\$ 89,178 bilhões), porém, com menos intensidade que no cenário simulado de redução apenas de barreira não tarifária, o mesmo ocorrendo com o resto da América Latina. Os ganhos totais de bem-estar no cenário 4 também ultrapassariam US\$ 1 trilhão, mostrando a importância da redução de BNT no processo de liberalização multilateral. Os dados do comércio global (MRE, 2016) em 2011 apontam que foram exportados em torno de US\$ 18 trilhões, ou seja, os ganhos do cenário 4 representariam aproximadamente $6,40 \%$ do total comercializado mundialmente.

Fugazza e Maur (2008) também encontraram resultados similares. Primeiro, as simulações que incorporam BNT são, em conjunto, de uma ordem de grandeza 
completamente diferente do que aquelas que consideram somente as tarifas de importação, visto que são de mais difícil mensuração e envolvem uma ampla gama de medidas. Os resultados no cenário que engloba tanto a redução tarifária como a redução de BNT são qualitativamente não muito diferentes do cenário que só incorpora redução de BNT, como foi encontrado neste estudo também. Isso é explicado pela predominância do efeito de eficiência, conforme destacam os autores.

A variável ams é semelhante a um choque tecnológico. Quando há um choque, a suposição implícita é feita de uma troca de fornecimento, resultando em quantidade extra produzida sem custo extra. Isso gerará ganhos substanciais de bem-estar (FUGAZZA e MAUR, 2008). Assim, esse componente é responsável pelo fato de que os efeitos do bem-estar sob o cenário que incorporam BNT são distribuídos de forma muito diferente do que sob o pressuposto dos cenários que incorporam apenas tarifas. Para várias regiões, isso implica uma mudança na direção dos efeitos do bem-estar.

\subsection{ANÁLISE DE SENSIBILIDADE}

Nas simulações econômicas com modelos de equilíbrio geral computável, os resultados são muito influenciados pelas hipóteses que se fazem para alguns parâmetros e pelos choques em variáveis exógenas. Portanto, é indispensável analisar a variação desses elementos para verificar o quanto eles influenciam os resultados endógenos e dar credibilidade às conclusões acerca dos resultados encontrados (FEIJÓ e STEFFENS, 2015). Isso é feito por meio da análise de sensibilidade, um importante instrumento para verificar a robustez dos resultados encontrados pelos modelos EGC. Nesse trabalho, é utilizada a análise de sensibilidade sistemática do software RunGTAP, em que o modelo é resolvido várias vezes para os diferentes valores dos parâmetros ou choques, dentro de um intervalo, e a distribuição dos valores obtidos para cada variável endógena é resumida por meio da sua média e desvio padrão (FEIJÓ e STEFFENS, 2015).

As três elasticidades de substituição incluídas na análise foram elasticidade de substituição entre os insumos domésticos (ESUBD), elasticidade de substituição entre os insumos domésticos e importados (ESUBT) e elasticidade de substituição entre os fatores primários (ESUBVA), e foi aplicado um choque conjunto de $50 \%$ nestas. A variável endógena escolhida para análise foi o indicador de bem-estar EV, que mostra a variação no equivalente da renda do consumidor regional, e o intervalo de confiança foi determinado pela Desigualdade de Chebyshev ${ }^{5}$ com $89 \%$ de confiança. Nas tabelas abaixo são apresentados os resultados para cada cenário simulado no estudo.

5 A desigualdade diz que, indiferentemente da distribuição na variável Y, para cada número positivo e real $k$, a probabilidade de que o valor de $Y$ não esteja dentro de $k$ desvios padrões (DP) da média (M) é inferior a $1 / \mathrm{k} 2$. Logo, com $89 \%$ de confiança, a média está dentro do intervalo entre $\mathrm{M} \pm 3{ }^{*} \mathrm{DP}$. 


\section{Tabela 11 - Análise de sensibilidade nos parâmetros de elasticidade sobre o bem-estar (em US\$ milhões)}

\begin{tabular}{lccccc}
\hline Regiões & Efeito Normal & Média & Desvio Padrão & \multicolumn{2}{c}{ Intervalo de Confiança } \\
\hline Brasil & 3.245 & 3.287 & 493,00 & 1.808 & 4.766 \\
CAIRNS & 5.118 & 5.163 & 939,00 & 2.346 & 7.980 \\
EUA & -4.676 & -4.815 & 1.553 & -9.474 & $-156,00$ \\
China & 28.650 & 28.741 & 2.898 & 20.047 & 37.435 \\
EU_28 & 6.852 & 6.814 & 1.398 & 2.620 & 11.008 \\
Resto da AL & $-67,00$ & $-68,00$ & 112,00 & $-404,00$ & 268,00 \\
Resto Mundo & 26.117 & 26.084 & 2.273 & 19.265 & 32.903 \\
\hline
\end{tabular}

Fonte: Elaboração própria a partir dos dados do GTAP.

No primeiro cenário, de redução de $50 \%$ de tarifas multilateralmente, apenas a região resto da América Latina apresenta inversão de sinal entre o limite inferior e superior do intervalo de confiança, o que sinaliza indeterminação no resultado do efeito de redução tarifária, visto que a variável EV se mostra relativamente dependente dos valores dos parâmetros de substituição. Todas as outras regiões incluídas no estudo apresentam o mesmo sinal entre o limite inferior e superior, indicando robustez no modelo. No caso do Brasil, os ganhos de bem-estar poderiam chegar a US\$ 4,766 bilhões, e a China poderia apresentar ganhos de até US\$37,435 bilhões.

\section{Tabela 12 - Análise de sensibilidade nos parâmetros de elasticidade sobre o bem-estar (em US\$ milhões)}

\begin{tabular}{lccccc}
\hline Regiões & Efeito Normal & Média & Desvio Padrão & \multicolumn{2}{c}{ Intervalo de Confiança } \\
\hline Brasil & 6.671 & 6.815 & 1.393 & 2.636 & 10.994 \\
CAIRNS & 8.342 & 8.441 & 2.197 & 1.850 & 15.032 \\
EUA & -8.207 & -8.463 & 3.237 & -18.174 & 1.248 \\
China & 56.134 & 56.315 & 6.374 & 37.193 & 75.437 \\
EU_28 & 10.063 & 10.275 & 2.961 & 1.392 & 19.158 \\
R. AL & $-969,00$ & $-960,00$ & 218,00 & -1.614 & $-306,00$ \\
R.Mundo & 37.979 & 37.931 & 4.307 & 25.010 & 50.852 \\
\hline
\end{tabular}

Fonte: Elaboração própria a partir dos dados do GTAP.

No segundo cenário, de liberalização total de tarifas, a única ambiguidade de resultado encontrada é para os Estados Unidos. Os ganhos brasileiros poderiam alcançar US\$10,994 bilhões, e, no caso chinês, poderiam ser de até US\$75,437 bilhões. 
Tabela 13 - Análise de sensibilidade nos parâmetros de elasticidade sobre o bem-estar (em US\$ milhões)

\begin{tabular}{lccccc}
\hline Regiões & Efeito Normal & Média & Desvio Padrão & \multicolumn{2}{c}{ Intervalo de Confiança } \\
\hline Brasil & 26.410 & 26.394 & 470,00 & 24.984 & 27.804 \\
CAIRNS & 143.259 & 143.164 & 1.886 & 137.506 & 148.822 \\
EUA & 97.299 & 97.597 & 3.269 & 87.790 & 107.404 \\
China & 57.265 & 57.194 & 5.447 & 40.853 & 73.535 \\
EU_28 & 435.687 & 436.423 & 4.861 & 421.840 & 451.006 \\
R. da AL & 8.589 & 8.539 & 329,00 & 7.552 & 9.526 \\
R. Mundo & 273.715 & 272.905 & 6.482 & 253.459 & 292.351 \\
\hline
\end{tabular}

Fonte: Elaboração própria a partir dos dados do GTAP.

Quando analisado o cenário de liberalização somente de BNT, verifica-se total robustez do modelo, com todas as regiões apresentando o mesmo sinal entre o limite inferior e superior do intervalo. Neste caso, os ganhos do Brasil poderiam alcançar a até US\$27,804 bilhões, enquanto os ganhos do grupo de CAIRNS poderiam chegar a US\$ 148,822 bilhões, e da União Europeia a até US\$ 451,006 bilhões.

Tabela 14 - Análise de sensibilidade nos parâmetros de
elasticidade sobre o bem-estar (em US\$ milhões)

\begin{tabular}{lccccc}
\hline Regiões & Efeito Normal & Média & Desvio Padrão & \multicolumn{2}{c}{ Intervalo de Confiança } \\
\hline Brasil & 33.842 & 33.961 & 1.564 & 29.269 & 38.653 \\
CAIRNS & 151.414 & 151.451 & 3.072 & 142.235 & 160.667 \\
EUA & 89.178 & 89.199 & 5.234 & 73.497 & 104.901 \\
China & 116.858 & 117.041 & 11.150 & 83.591 & 150.491 \\
EU_28 & 443.763 & 444.575 & 6.582 & 424.829 & 464.321 \\
R. da AL & 7.771 & 7.747 & 497,00 & 6.256 & 9.238 \\
R. Mundo & 313.739 & 313.103 & 10.235 & 282.398 & 343.808 \\
\hline
\end{tabular}

Fonte: Elaboração própria a partir dos dados do GTAP.

O último cenário, de liberalização total de tarifas e parcial de BNT, também indica total robustez do modelo, com todas as regiões apresentando o mesmo sinal entre o limite inferior e superior do intervalo de confiança. Os ganhos de bem-estar do Brasil nesse cenário poderiam chegar a US\$ 38,653 bilhões, do grupo de CAIRNS a US\$ 160,667 bilhões, da China a US\$ 150,491 bilhões e da União Europeia a US\$ 464,321 bilhões. 


\section{CONCLUSÕES}

$\mathrm{O}$ artigo criou quatro cenários, todos no âmbito multilateral, por meio do software GTAP, para verificar os possíveis efeitos da conclusão da rodada de Doha da OMC. O primeiro apresentou redução parcial de 50\% das tarifas de importação; o segundo, liberalização tarifária total; o terceiro, redução de 50\% de BNT; e, por último, liberalização total de tarifas combinado com redução de $50 \%$ de BNT.

Os resultados das exportações brasileiras mostram que a liberalização tarifária beneficiaria principalmente os setores primários e agroindustriais, em detrimento das manufaturas, o que vem ao encontro da literatura existente. Já a redução multilateral das BNT afetaria especialmente os setores industriais, de maior conteúdo tecnológico. O último cenário é o único em que todos os setores aumentariam as exportações, com destaque para os expressivos aumentos do setor de pecuária $(536,27 \%)$, agroindústria $(436,4 \%)$ e manufaturas de alta intensidade tecnológica (128,49\%).

A análise de bem-estar aponta para ganhos para o Brasil em todos os cenários. Porém, a comparação do primeiro cenário (redução de 50\% de tarifas) com o terceiro cenário (redução de $50 \%$ de BNT) mostra que os ganhos com a redução de BNT chegariam a ser mais de oito vezes maiores. $\mathrm{O}$ último cenário é o que mais beneficia o Brasil, com ganhos de US\$33,861 bilhões, mais de 10 vezes maiores que os ganhos do primeiro cenário, mais de cinco vezes maiores que o segundo e $22 \%$ a mais que os ganhos do terceiro cenário. Quando analisado o efeito total mundial de bem-estar, verificam-se novamente ganhos expressivamente maiores quando reduções de BNT são incluídas nas simulações, caso dos cenários 3 e 4, em que os ganhos ultrapassariam US\$ 1 trilhão. Para fins de comparação, esse valor representa 6,40\% do total do comércio mundial para o ano de 2011, o que demostra a importância da redução de BNT no processo de liberalização multilateral.

Para testar a robustez dos resultados, foi realizada a análise de sensibilidade sistemática do software RunGTAP. A variável endógena escolhida para análise foi o indicador de bem-estar EV, e o intervalo de confiança foi determinado pela Desigualdade de Chebyshev, com 89\% de confiança. Os intervalos de confiança mostram que, no primeiro cenário, apenas uma região, resto da América Latina, apresentou sinal diferente entre o limite inferior e o superior. No segundo cenário, novamente uma região apresentou resultado ambíguo - os Estados Unidos. Já no terceiro e quarto cenários, todas as regiões apresentaram o mesmo sinal entre o limite inferior e o superior do intervalo de confiança, indicando a robustez do modelo.

Os resultados do trabalho sinalizam que os ganhos globais de uma liberalização multilateral que leve em consideração a redução de BNT, ao lado das tarifas de importação, seriam muito maiores, beneficiando tanto países emergentes quanto 
desenvolvidos. Nos cenários 3 e 4, todas as regiões incluídas no estudo apresentaram ganhos de bem-estar, diferentemente dos dois primeiros cenários, que simularam apenas reduções tarifárias, em que algumas regiões perderam bem-estar. Destaca-se, ainda, que nos cenários que incluíram a redução de BNT a análise de sensibilidade demonstrou total robustez do modelo. Isso mostra a atual relevância dessas barreiras ao comércio internacional e a necessidade de combatê-las para que se tenha um avanço significativo em termos de ampliação do comércio e bem-estar a partir das negociações da Rodada de Doha. Sendo assim, sugere-se que postura do Brasil nas mesas de negociações da OMC seja direcionada para uma maior liberalização multilateral do comércio, uma vez que os ganhos para o país poderiam ser muito expressivos.

Dentre as limitações do presente trabalho, está a não incorporação de economias de escala para avaliar o impacto no setor de manufaturas, especialmente o de alta intensidade tecnológica. Estudos que incorporam economias de escala, diferenciação de produto e competição imperfeita nas suas análises tendem a mostrar resultados mais expressivos em relação aos baseados em competição perfeita e retornos constantes de escala. Harrison, Rutherford e Tarr (1997) salientam, no entanto, que esses ganhos adicionais estão mais associados com mark-ups mais elevados e com a incorporação de outras mudanças, como elasticidades, do que com a mudança do regime em si. De qualquer forma, tem-se como perspectiva para trabalhos futuros a utilização de economias de escala e competição imperfeita para ter uma dimensão mais precisa dos efeitos da rodada de Doha da OMC.

\section{REFERÊNCIAS}

ALMEIDA, F. M. Medidas não tarifárias e comércio internacional agrícola: os efeitos dos objetivos das notificações aplicadas aos acordos TBT e SPS. Tese (Doutorado em Economia Aplicada) - Universidade Federal de Viçosa, Viçosa, 2012.

APEC BUSINESS ADVISORY COUNCIL. Non-tariff barriers in agriculture and food trade in APEC: business perspectives on impacts and solutions. University of Southern California, Marshall School of Business. Los Angeles: nov. 2016.

ARÊDES, A. F.; PEREIRA, M. W. G. Efeitos da rodada Doha sobre o agronegócio e sobre a economia e o bem-estar no Brasil e no Mercosul. Revista de Economia \& Relações Internacionais, São Paulo, v. 7, n. 14, p. 37-49, 2009.

BERDEN, K. et al. Non-tariff measures in EU-US trade and investment - and economic analysis. Rotterdam: Ecorys, 2009. (Report for the European Commission).

BRASIL. MRE - MINISTÉRIO DAS RELAÇÕES EXTERIORES. Comércio Mundial 2011-2015. Departamento de Promoção Comercial e Investimentos. Divisão de Inteligência Comercial. Brasília, DF: MRE, 2017.

FEIJO, F. T.; ALVIM, A. Impactos econômicos para o Brasil de um choque tecnológico na produção de etanol. Economia, Brasília, v. 11, n. 3, p. 691-710, 2010. 
FEIJO, F. T.; STEFFENS, C. Comércio internacional, alocação do trabalho e a questão da desindustrialização no Brasil: uma abordagem utilizando equilíbrio geral computável. Revista da Economia Contemporânea, Rio de Janeiro, v. 19, n. 1, p. 135-161, 2015.

FIGUEIREDO, A. M. et al. Impactos dos subsídios agrícolas dos Estados Unidos na expansão do agronegócio brasileiro. Estudos Econômicos, São Paulo, v. 40, n. 2, p. 445-467, 2010.

FOCHEZATTO, A. Modelos de equilíbrio geral aplicados na análise de políticas fiscais: uma revisão da literatura. Análise, Porto Alegre, v. 16, n. 1, p. 113-136, 2005.

FUGAZZA, Marco; MAUR, Jean-Christophe. Non-tariff barriers in CGE models: How useful for policy? Journal of Policy Modeling, v. 30, p. 475-490, 2008.

FURTADO, A. T.; CARVALHO, R. Q. Padrões de intensidade tecnológica da indústria brasileira: um estudo comparativo com os países centrais. São Paulo em Perspectiva, São Paulo, v. 19, n. 1, p. 70-84, 2005.

GLOBAL TRADE ANALYSIS PROJECT. GTAP models: computable general equilibrium modeling and GTAP. Disponível em: <https://www.gtap.agecon.purdue.edu/models/cge_ gtap_n.asp $>$. Acesso em: 15 abr. 2017.

HARRISON, G.; RUTHERFORD, T.; TARR, D. G. Quantifying the Uruguay round. The Economic Journal, v. 107, n. 444, p. 1405-1430, 1997.

IEDI - INSTITUTO DE ESTUDOS PARA O DESENVOLVIMENTO INDUSTRIAL. O Brasil e os novos acordos preferenciais de comércio: o peso das barreiras tarifárias e não tarifárias. São Paulo: IEDI, mar. 2014.

KEE, H.; NICITA, A.; OLARREAGA, M. Estimating trade restrictiveness indices. The Economic Journal, v. 119, n. 534, p. 172-199, 2009.

RÊGO, E. C. L. Do Gatt à OMC: o que mudou, como funciona e para onde caminha o sistema multilateral de comércio. Revista do BNDES, Brasília, n. 6, 1996.

REIS, M. et al. A OMC continua promovendo o comércio de forma desigual: novas evidências a partir dos anos 1990. Revista Brasileira de Economia, Rio de Janeiro, v. 69, n. 3, p. 389-404, 2015.

RODRIGUES, F. R.; BURNQUIST, H. L.; COSTA, C. C. Escalada tarifária e exportações brasileiras da agroindústria do café e da soja. Revista de Economia e Sociologia Rural, Brasília, v. 49, n. 2, p. 295-322, 2011.

SAMPAIO, L. M. B.; SAMPAIO, Y. Prioridade brasileira entre acordos de livre comércio utilizando equilíbrio geral aliado à teoria dos jogos. Revista Economia, Brasília, v. 10, n. 3, p. 533-55, 2009.

SANTOS, V. F.; VIEIRA, W. C.; REIS, B. S. Efeitos redistributivos de transferência de renda e redução tributária nos setores agropecuário e agroindustrial. Revista de Economia e Agronegócio, Viçosa, v. 5, n. 4, p. 455-486, 2007.

SBARAI, N.; MIRANDA, S. H. G. Tarifas equivalentes de medidas não tarifárias sobre exportações brasileiras de carne bovina para a UE (2000-2010). Revista de Economia e Sociologia Rural, Brasília, v. 52, n. 2, p. 267-284, 2014.

UN COMTRADE - UNITED NATION COMMODITY TRADE STATISTICS DATABASE. Statistical division of the United Nations. New York: UN, 2017. Disponível em: <https:// comtrade.un.org/data/>. Acesso em: 20 abr. 2017. 